\title{
TOOL BASED PSYCHOLOGY AS A PHILOSOPHY OF TECHNOLOGY
}

\author{
Irina Verenikina' \& Edward Gould ${ }^{2}$ \\ ${ }^{1}$ Russian Academy of Sciences \\ ${ }^{2}$ Department of Business Systerns, \\ University of Wollongong \\ email: e.gould@uow.edu.au
}

\begin{abstract}
This paper examines the influence of psychology in the area of human computer interaction and information technology in general. Cognitive psychology is critically examined and its shortcomings in guiding technological development outlined. As a possible alternative to the cognitive approach the Vygotskian psychological framework of activity theory introduced. This Russian developed theory may provide a more extensive basis for human computer interaction and holds some promise as a framework for the development of computer systems more compatible with the humans that use them.
\end{abstract}

\section{KEYWORDS}

Activity Theory, Human Computer Interaction, Psychology

\section{INTRODUCTION}

The basis for a philosophy of technology has always been hampered by a tendency to use the most 'advanced' machine of the day as a paradigm for human cognition As Bødker (1997) points out, it was once the steam engine but in the last few decades the computer has provided an example of a machine which is seemingly able to perform mental tasks in contrast to the preceding 'all-manual' machines. It has even given rise to a branch of psychology known as cognitive science. This concept of the machine as a model for human cognition is a rather curious reversal of the true role of any machine, that of as an assistant or mediator of daily activities. There is no reason to regard the computer as anything more than a machine developed from a long line of tools used to assist human activity.

\section{Background}

The explosive growth in the use of information technology is having a profound effect on the work practices of humans. In order to increase the benefits of information technology computer systems and their interfaces must be designed as tools which are compatible with the capabilities of their human users. Much research has been aimed at providing technicians and programmers with a proper picture of the user, most specifying the psychological features which should be taken into account when developing an interface. However, there is still no agreement on the optimal psychological approach to this complicated area. Up to recent times Western cognitive psychology has been the main influence in the development of information technology interfaces but attempts to apply it to human computer interaction have had limited success due to the narrow focus of this discipline. It has concerned itself more with the cognitive process and projected this into a philosophy of human-computer interaction which is based on the computer analogy of input-processing-output to describe the functioning of the human mind. The reason for this is the apparent unanimity between this branch of psychology and the architecture of the computer both in concept and vocabulary. There is a readily identifiable compatibility between human and computer "components" when computer devices such as the keyboard, memory and VDU are compared to disembodied human devices such as the eyes, brain and fingers. This tempting analogy has led to a concept of human-computer interaction (HCI) which treats the computer and its human operator as equals. The logical extension of this line of reasoning is that ultimately it would be possible to build a computer with the ability to outstrip the human mind. This has given rise to fields dedicated to the 'cybernaut' quest such as the study of artificial intelligence and knowledge based systems. They have mostly had limited success although recently the perception of their ability has been exaggerated by the development of a machine capable of humiliating the world chess grandmaster. Philosophically the dream of the technophile was realised in this chess contest, the role of the machine having been reversed from that of a tool for enhancing life to that of a machine which seeks to dominate it. The practical outcome of this general approach is that any experiment to examine the compatibility of a computer with a human is restricted to an interaction between these two components alone to the exclusion of the context of the real life interaction of the human work activity. This can be seen in the classic $\mathrm{HCI}$ experimental model shown in figure 1. 




Figure 1 HCI Experimental Model

\section{Is There An Alternative Model?}

This general cognitive approach has led $\mathrm{HCI}$ experimenters to a frustrating lack of design tools suitable for predicting human reaction to information technology. It is essential to explore the processes where information technology intercedes in the work practices of humans. A branch of psychology developed by Lev Vygotsky in the beginning of this century provides a different philosophical approach and opens new perspectives for constructing experimental research into this problem. Vygotskian psychology and activity theory take a much broader view of human psyche as being the product of cultural and social forces (Vygotsky, 1978). From its perspective people are not a collection of cognitive processes but in a complex interaction with the world directed to the process of living. In this approach the main feature of the psyche is the active position of human beings toward the world in which they live. This world and its social context is referred to as 'objective reality' and consists of all the things (objects) which contribute to human existence such as events, happenings, interactions, etc. Humans are continually changing the objects and creating artefacts - tools. This complex interaction of individuals with their surrounding has been called activity and regarded as the fundamental unit of analysis of human psyche (A.Leontiev, 1978, C.Tolman, 1988). Activity is motivated by the objects to be changed. Object orientedness and mediation by tools is one of the most distinguishing characteristics of activity. Tools are seen as having extended human ability to achieve the goals of an activity, that is, to change objects in the world. This theory treats tools as a means of satisfying real needs and achieving corresponding goals. This leads us to a different experimental scheme, one with many more elements which emphasise the role of the computer as a tool embedded in human activity, both mental and physical.

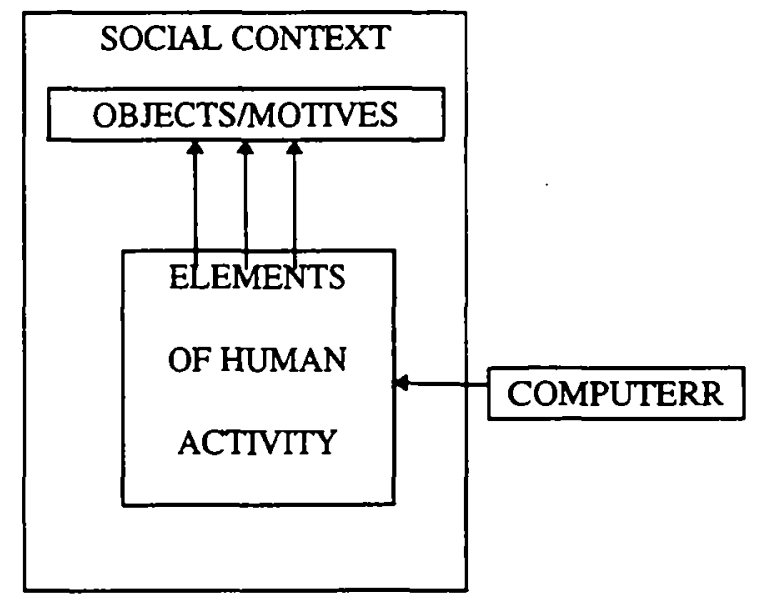

Figure 2 Activity Theory Framework

\section{COGNITIVE PSYCHOLOGY AS A PHILOSOPHICAL BASIS FOR TECHNOLOGY}

Recent trends in $\mathrm{HCI}$ research heavily favour exploration of the cognitive processes, due to what is seen as the qualitative new form of artefact embedded in the use of the computer - the automation of brain work compared to the automation of hand-work. Many of the problems associated with the information processing model of cognitive science, evident in such areas as expert systems and artificial intelligence, can be seen to be related to the incompleteness and narrow base of this cognitive approach. Computerised automation, where the operational aspects of human mental work are removed from the 'human sphere' and transferred to technology, are part of, and not 
significantly different to, the transference of human physical work to technology which has been going on for thousands of years. When operations are carried out by technology, it still realises the wishes of the subject, and hence involves the human psyche.

The first real possibility of building a nervous system computationally equivalent to the human mind was elevated from the realms of science fiction by the construction of electronic computers in the late 1940's. The view of a computer as a 'thinking' machine was based on Turing's concept of thinking as an algorithmic process with the compelling analogy between human and machine of input, processing and output. This view, held by many artificial intelligence theorists who see computers as substitute humans with identical capabilities is, however, fraught with problems. As Karpatschof (1992) explains: 'It is meaningless to expect a full correspondence between a human and a machine. Not only is a machine lacking in the most important human characteristics, the machine has also many attributes we don't find in a human being. That is actually the reason for making it in the first place.' Dreyfus and Dreyfus (1986) also share similar beliefs when they say that : 'computers as reasoning machines can't match human intuition and expertise, so in determining what computers should do we have to contrast their capacities with the more generous gifts possessed by the human mind.' In spite of comments like these, a great deal of effort has been put into the field of artificial intelligence over the last decades without, it seems, ever turning to the various branches of psychology as a source model for ' human intelligence', the very thing they were purporting to duplicate artificially.

\section{Cognitive Science}

Cognitive science emerged in the mid 1970s out of a realisation that a multi-disciplinary approach was required if we were to understand higher mental processes and structures. It attempts to bring together what is known about the mind from many academic disciplines: psychology, linguistics, anthropology, philosophy, and computer science. The assumption is that all important human insight can be reduced to principles and rules - that machines can think (McCorduck, 1979). Cognitive science asks about thought and thinking, about consciousness and computation.

In line with cognitive science the concept of cognitive psychology emerged in the USA and UK as an outcome of computer technologies by assuming that the computer can provide a new paradigm for psychology. Cognitive psychology therefore, analyses human mental processes with the aim of understanding human behaviour. Information theories of perception, attention, memory, emotions and personality are developed. Humans are viewed as an 'active process of information eternally striving to sum up and interpret the incoming data and to interpret and reproduce the information stored in its memory through a variety of algorithms and strategies' (Tikhomirov, 1988). In this trend psychology at large was declared a science of information processing. Although artificial intelligence, cognitive science and cognitive psychology have different aims and methods of investigation, they basically all share an understanding of human thinking as information processing. In addition they interpret cognition or intelligence as the most important constituent property of the psychic processes. When using the concept of cognitive approaches in the following we do not distinguish between the three of them.

\section{Artificial Intelligence}

Artificial Intelligence (AI) aims at creating computer software and hardware that imitates the human mind or functions of the human brain. The role of the computer is to replace the human in intellectual spheres, such as mathematical calculations, manipulation of numbers and letters, decision-making, problem-solving, and so on. According to Feigenbaum (1977) some work towards the construction of intelligent artefacts such as expert systems, which purport to be models of experts' problem solving and expert knowledge automatised in information programs. Others view artificial intelligence as 'theoretical psychology' seeking information processing models of human thoughts leading us to a view of $\mathrm{AI}$ as the study of 'cognitive' phenomena within the machine.

Two related points of critiques have emerged. One argument is in opposition to the very rational conception of human beings embedded in the cognitive approaches emerged from a meta-theoretical point of view (e.g. Dreyfus and Dreyfus 1986). Also some empirical studies suggest that the design process is characterised by intuition and imagination as the driving force of the process, rather than a rational problem-solving strategy (Aboulafia et al, 1993). In most cases the designers relied upon their intuitive understanding of the system, gained from previous experience. Another design study showed similar results. Bansler and Boedker (1993) found a gap between the way systems development is represented in structured analysis by Yourdon and DeMarco and the way in which it was carried out. Designers did not follow the design procedures prescribed but, in general, had a very pragmatic attitude towards using it. 
As well as arguing against the limited understanding of problem-solving as being a rational rule-based process of thinking, the studies indicate that the way methods are used is related to the context of application. A general view by the designers in one of the studies were that a main hindrance in modelling techniques was that these techniques didn't take into account social aspects, such as team work and organisational issues (Aboulafia et al 1993). They suggested that 'a bag of tools' from which they could pick and choose, would be useful, so they could adapt different methods to their own purposes and integrate these into their own design processes.

Another criticism is related to the attempt to use the same concepts and methods as properties of both systems and human beings. Bansler and Boedker's (1993) study found a possible limitation of modelling methods 'inherent' in the methods themselves. The basic idea of structured analysis is to model organisations and work processes as information processing systems with the aim of producing detailed functional descriptions of tasks and operations. There is no distinction made between the way people act and the way machines function. Consequently, the method has a number of 'defects' such as reducing problem solving and judgement to mere rule following, ignoring informal communication, underestimating of errors, giving no help to analysing work organisation, etc. And as Bansler and Boedker (1993) stress, while is makes sense to understand a computer system in terms of data processes, it is doubtful whether it makes much sense to understand work in these same terms.

It is becoming more obvious to even die-hard AI proponents that the information processing units in humans and computers are indeed different. Much criticism therefore, has emerged of this cognitive science understanding of human cognition, and a question is if it possible to overcome the problem within the framework of cognitive science.

\section{LIMITATIONS OF THE COGNITIVE SCIENCE APPROACH}

Winograd and Flores (1986) argue that 'contrary to widespread current belief - one cannot construct machines that either exhibit or successfully model intelligent behaviour'. They go on to say that 'the essence of intelligence is to act appropriately when there is no simple pre-definition of the problem or the space of states in which to search for a solution. Rational search within a problem space is not possible until the space itself had been created, and is useful only to the extent that the formal structure corresponds effectively to the situation.' Their analysis is formulated on the philosophy of Heidegger which proposes as a basis for understanding cognition should be built around our 'being-in-the-world' which challenges the dominant view of cognition based on the systematic manipulation of representations.

Brooks (1991) states that 'out of the soup of ideas on how to build intelligent machines the disembodied and nonsituated approach of problem-solving search systems emerged as dominant, at least within the AI community'. Search was extended to make use of heuristics to prune the search space and before long the focus became the control of search. No doubt the popularity of search was due to the ease with which its basic tree structure can be programmed on a digital computer but it is this opportunism that has taken it further away from the very thing that it set out to imitate by amplifying the abstraction away from connectedness to the world. He criticises the branch of AI known as Knowledge Engineering for concentrating much of its energies on anomalies within formal systems which are never used for any practical task. He goes on to say that there is an implicit assumption that someday the inputs and outputs will be connected to something that will make use of them. The heuristic approach to problem solving is examined by Dreyfus \& Dreyfus (1986) who found that only beginners use this approach. As people become more proficient in their field to the level of expert they intuitively move away from using abstract rules to being able to recognise thousands of special cases. Brookes (1991) also criticises the view of knowledge as being stored in a way that is independent of the circumstances in which it was acquired. In comparing human and artificial thought he says:

'Biological systems run on massively parallel, low speed computation, within an essentially fixed topology network with bounded depth. Almost all Artificial Intelligence research, and indeed almost all modern computation, runs on essentially Von Neumann architecture, with a large, inactive memory which can respond at very high speed over an extremely narrow channel, to a very high speed central processing unit which contains very little state. When connections to sensors and actuators are also considered the gap between biological systems and our artificial systems widens.'

These sentiments are echoed by Suchman (1987) when she says that the question of theoretical versus practical criteria of adequacy for machine intelligence is rendered moot by the problems involves in constructing a device that 
even appears to behave in ways that are purposeful or intelligent'. Dreyfus (1992) points out that the belief that both human beings and computers are information processing units presupposes that the mechanisms underlying them are essentially the same. Computers, he says deal with facts but humans are the source of facts, in a world of facts created by them in the process of living. He goes on to say: "This human world with its recognisable objects is organised by human beings using their embodied capacities to satisfy their embodied needs. There is no reason to suppose that a world organised in terms of these fundamental human capacities should be accessible by any other means.' This concept of embodiment or situatedness has been addressed by cognitivists as a possible solution to the AI problem. Given this criticism and concern about the use of cognitive science as a philosophical basis for information technology the next section looks at an alternative approach.

\section{VYGOTSKIAN PSYCHOLOGY AND ACTIVITY THEORY}

\section{Introduction}

Activity theory is a psychological theory that had its beginnings in the German philosophy of Kant and Hegel and was later developed by the Russian psychologists L.S. Vygotsky, A.N. Leontiev and others during the first half of this century. It is a theory which treats the individual as an outgrowth of social forces rather than the autonomous being.

There is evidence of the influence of a great many other philosophers such as Janet, Wallon, Piaget, Wertheimer, Tolman with his neobehaviourism and particularly John Dewey with his work on pragmatism. Others include James with his work on substantialism and Spinoza, a favourite of Vygotsky, with his belief that mental and neuropsychological phenomena were two attributes of the one substance. Although Vygotsky and his followers were accustomed to citing Marx frequently, it is difficult to judge whether his ideas had much influence on the development of the theory, due to the fact that it was generally accepted at the time that Marxist-Leninist philosophy had to be used as the basis for all branches of scientific study irrespective of whether it had any relevance to the topic being studied. The theory has become familiar to western psychologists through the work of Cole and Maltzman, 1969, Wertsch, 1981, 1994, Raeithel, 1990, Kuutti, 1990, 1992, Engestrom, 1990, Kaptellinin, 1992, 1994 and Zinchenko, 1992.

\section{Overview}

Vygostkian psychology (Vygotsky, 1978, 1981) stated that human mind is constructed through a subject's interactions with the world and is an attribute of the relationship between subject and object. Consciousness is neither reducible to behaviour nor separate from it, but instead is an attribute of the organisation of practical activity. It is the process that organises behaviour. Vygotsky also claimed that consciousness is not an attribute of any particular state or process, but is an attribute of the way in which states and processes such as attention and memory, are organised and functionally related both to behaviour and to each other. It was consciousness that established the connection between the various processes, it both creates them and transforms them. In particular the nature of a goal-directed activity transforms its user. He thus introduced the idea of externally mediated activity, actions that involve the use of external means to reach a goal. This led to the idea that mental processes could only be understood if we understand the tools and signs that mediate them.

\section{Tool Mediation}

A basic tenet of Vygotsky's theory was that tools occupy a mediating role, they mediate human reaction with the world. Tools therefore are social objects with certain modes of operation developed socially in the course of labour and are only possible because they correspond to the objectives of a practical action. Tools can be either external (physical, technical) such as artefacts, instruments and machines or internal (psychological) such as laws, signs, procedures, methods and language. Physical tools are designed to manipulate physical objects (e.g. hammer) while psychological tools are used by humans to influence other people or themselves (e.g. concepts, advertisements, calenders). Since psychological tools are included in the process of behaviour they alter the entire flow and structure of mental functions. Similarly the physical tool (including computers) alters the process of natural adaptation by determining the form of labour operations. A physical tool can be seen as an instrument of labour, a thing which is interposed between a person and the object of their labour and which 'serves as the conductor' of their activity. 


\begin{abstract}
Although tools expand our possibilities to manipulate and transform different objects they also have a limiting effect in that the object can only be manipulated within the limitation of the tool.

His basic idea was of historically evolving object-oriented practical activity carried out by humans determining the genesis, structure and contents of the human mind. Vygotsky derived his original ideas from an analysis of the features of specifically human activity - work activity, productive activity carried on with tools, activity that is indigenously social i.e. developed under conditions of cooperation and sharing by people. He had isolated the two principal interrelated features basic to psychology. These were the 'instrumented' (tool mediated) structure of human activity and its incorporation into the system of interrelationships with other people. This means that the higher mental functions in humans originate only in the interaction of people with people. Vygotsky did not make a complete analysis of the specific concept of activity, but his theoretical approach pre-supposed the concept as one of its fundamental building blocks. The theoretician who followed up Vygotsky's work and is most closely associated with the development of a coherent activity theory framework was A.N.Leontiev.
\end{abstract}

\title{
Activity Theory Structure
}

Activity, according to Leontiev $(1978,1981)$ is not a reaction and not a totality of reactions but a system that has structure, its own internal transitions and transformations, its own development. Activity brings together in one unit of analysis both internal, psychological phenomena and an external, objective world. Leontiev was opposed to the separation of what goes on in our mind with what goes on around us and sought to examine the profoundly unique nature of the psychic phenomena that distinguishes it from other 'objective phenomena of reality' (the real world). He sums it up thus: '...our activity seems to occur as it were on two primordially different (and) opposite planes:

- on a subjective ideal plane (i.e. the activity of our consciousness and thought) and

- on an objective plane - the plane of the phenomena of the material world, i.e. our external material activity, the movements of our body, and those internal processes which are their physiological basis.'

The initial and fundamental form of human activity is external, practical activity. The internal plane of activity, inner mental operations and actions, is formed in the process of internalisation. Internalisation is the transition in which external processes with external, material objects are transformed into processes that take place at the mental level, the level of consciousness. During this transition these processes undergo special changes - they become generalised, verbalised, abbreviated; and most importantly, they become the means for further development that transcends what is possible with external activity.

Activity here has its general collective meaning, we need to deal with specific activities, each of which answers a definite need of the subject, is directed toward an object of that need, is extinguished as a result of its satisfaction, and is produced again in other altogether different conditions. Activity types can differ among themselves depending on the difference between their objects. The object of an activity Leontiev says is its true motive, which may be either real or imagined, thus activity does not exist without motive. He called a process an action if it is subordinated to the representation of the result that must be attained, that is if it is subordinated to a conscious purpose. He goes on to say that just as the concept of activity is related to the concept of motive then the concept of purpose is related to the concept of action. Human activity he explains, does not exist except in the form of action or a chain of actions with one and the same action accomplishing various activities and may be transferred from one activity to another. This means that activity is usually accomplished by a certain complex of actions subordinated to particular goals that may be isolated from the general goal. In other words, these actions are seen as goal-directed processes but, in society, these processes are rarely related directly to the goal where even the simplest division of labour leads to 'goal-isolation'. The needs of a person working on an assembly line are not satisfied by the immediate results of producing something, but by a share of the results of the collective activity in the form of salary. The actions that realise activity are aroused by its motive but directed towards a goal. The means of accomplishing actions Leontiev called operations. Just as activity is related to goals, operations he saw as related to conditions. In a case where the goal remains the same but conditions change then it is only the operational content of the action that changes. Actions and operations he saw as the 'units' of activity.

Thus Leontiev introduced a three level structure of activity. Associated with each level is a specific type of unit, the first of which is the unit of activity (detyatel'nost). Here 'activity' means the real activities as opposed to human activity in general and includes such things as labour, formal education and play. It is not determined by the physical context in which humans function but is a socio-cultural creation imposed on the context by the participants. The 
next level of analysis is the action (deistvie) which, although related to an activity at a particular time can vary independently of it and is transferable to other activities. A particular action could be executed while a person participates in different activities such as work, play or education. The third level of analysis is the operation (operatsiya) and this relates to the concrete conditions under which the action is carried out and includes the resources for reaching the goal. The goal, which is embedded in a specific set of conditions, comprises the task of the activity. This can be summarised schematically:

$\begin{array}{lll}\text { Activity - } & \text { Motive } \\ \text { Actions - } & \text { Goals } & \\ \text { Operations } & -\quad \quad \text { Conditions (Tasks) }\end{array}$

This structure can however, be divided in a way which depends on the characteristics of each component and on their inter-relationships which in turn are mobile and changeable. In an integrated activity the within-level and betweenlevel organisations are realised by the integration and unification of the functionally defined processes.

\section{HUMAN COMPUTER INTERACTION AND ACTIVITY THEORY}

The diverse nature of the many current cognitive techniques used in $\mathrm{HCI}$ design and evaluation makes the job of classifying and identifying them as models, methods or architectures difficult. Over the last fifteen years a large number $\mathrm{HCI}$ design tools and techniques have been proposed. Howes (1994) has identified twenty three different approaches, each oriented towards a small and manageable part of the overall issue of the way humans interact with computers.

The psychological theory expounded by Vygotsky and extended by followers such as Leontiev and others has been discovered by the international community of researchers in human-computer interaction and computer supported cooperative work over the last ten years. For example see Bannon \& Bødker, 1991; Bødker, 1991; Draper, 1993; Engestrom. 1990; Gould \& Verenikina, 1995; Kaptelinin, 1992; Kuutti, 1992; Nardi, 1992, 1997. Its generally welldeveloped frameworks may prove more beneficial than traditional cognitive psychology in the analysis of the reaction between humans and machines.

Kaptelinin (1992) has identified four points which are of central importance to activity theory and the special role that tools in general play within this framework.

- the identification of the specific psychological functions of computer tools and how they differ from other kinds of artefacts,

- consideration of the psychological nature of the functionally equivalent processes involved, more specifically whether they are activities, actions or operations since this can affect the design and training strategies,

- an analysis of the development of users from novice to expert as they develop new skills and abilities with experience,

- the relationship between computer tools and cultural influences which can render successful systems in one social setting ineffective in another

It stresses the vertical integration of psychological analysis and stresses the following points usually missed by the cognitive approach:

- the goal which is determined by the nature of human actions, their structure and performance,

- the role of mechanisms underlying the integration of a computer tool into the structure of activity,

- the importance of developmental aspects of human computer interaction,

- the significance of social interactions surrounding computer use (Kaptelinin, 1992).

Activity theory provides a paradigm for the description and understanding of the way humans deal with computers within the context of the user's environment. Recently, $\mathrm{HCI}$ researchers came to understanding of the importance of the context in which computer-mediated activities take place mainly due to the work of Lucy Suchman (1987). However, contextual factors are rather elusive and difficult to identify (Nardi, 1997, Pennel et al, 1997). It is here 
that activity theory helps by providing a theoretical framework for describing context of human activity through the structural analysis of the activity, in particular - the highest level of it - motivation. Definition of the motive as the object of transformation within the activity brings together psychological factors (drive, motive, meaning of the activity) and contextual factors (objects as artefacts belonging to a particular social cultural-historical context). In this respect the activity theory approach is not a theory which substitutes for other approaches but it brings a more broader, holistic, integrative philosophical view of the use of information technology by humans.

It also should be noted that activity theory shares a few common ideas with contemporary developed task analysis, which presents a detailed description of individual actions and operations. Activity theory is based on a much broader set of structures dealing with the higher levels of activity and paying attention to integrative relationships between the actions of the activity.

\section{EXECUTIVE INFORMATION SYSTEMS INDIVIDUAL INTERFACE DESIGN}

Recently activity theory has been applied to the development of executive information systems interfaces ( Hasan , Gould and Hyland , 1998, Verenikina, Gould, 1997). This is a particularly promising area for applications since the development of executive information systems (EIS) present particular problems for the designer. Not only are the clients for whom the system is being designed not known, but they are of a disparate group with different ways of conducting business, making decisions, using data, arriving at conclusions, etc. For an executive to make use of an information system to improve management efficiency an interface compatible with individual management style is essential.

Software developers have been producing systems for many years which purported to be executive information systems. Unfortunately very few of these systems have been successful. The problem cited in the past has always been that the spreadsheet software on which the systems were usually based was not sufficiently sophisticated to deal with the problem. This, however, is no longer the case. Very sophisticated multidimensional databases are now capable of extracting complex combinations of the most obscure of data and presenting it in every imaginable way, all at considerable speed. The problem has changed from one of software engineering to one relating to the psychology of executive users. It has long been known that executives manage in their own particular style. It is also well known that these different styles need different types of information presented in different ways. The question is how do we go about finding out the best mesh of information and business management style so that an EIS is useful to an individual executive.

Existing research which studied personalities and tried to apply it to interface design were unsuccessful because of the difficulty in applying psychological studies of personality to this particular case - they were too far removed from the problem. One possible approach is based on the study of a personal profile of an executive. This profile will consist of an ensemble of the executive's business activities relating to the use of the EIS as a tool embedded in the activities. This will enable the information system to function as a tool for performing the activities and will enable designers to devise ways that an interface can be designed to extract, amalgamate and present information in a way that suits the business management style of the executive. Kaptelinin and Nardi (1997) have recently created an 'Activity Check List' for analysing the structure of activities. It is a good example of the operationalisation of activity theory concepts for practical use.

An example of the influence of identification of different levels of activities is shown in an information retrieval system design (Hyland, 1998). Activity Theory is used to present a more integrated view of the process of information retrieval and suggest how these problems and their solutions fit together. Hyland shows that implicit in much of the information retrieval research is the assumption that the person is engaged in the activity of locating data from a visualisation of some set of the data which is used to navigate and locate that subset which is required. However, using the specific meaning of 'activity' as applied in activity theory this assumption is incorrect. In such cases, the search for data would be an action that is carried out to complete the activity of writing a report or other broader based undertaking. Hyland goes on to say:

"The actual process of searching, the keystrokes used and so on, are the operations used and these depend on the conditions encountered by the user. This distinction between activity and action is not a trivial one. The supposition that most users are involved in the activity of locating data has led to many problems that have been raised in the literature. For users who have a clearly defined search and are familiar with the system being used, the main concern is that the system provides an appropriate level of recall and precision as quickly as possible. For such users it could be reasonably assumed that much of the search process would be carried out an operational level. For a user with a 
poor knowledge of the system, it cannot be assumed that this is the case. Such a user may shift the focus of his or her activity to the use of the information retrieval systems, placing the original activity in abeyance for the time being. If systems are to be used not at an operational level but as an activity in its own right, then system developers need to adopt a different focus in their system design. One example of this would be a change in the help that the system must provide to such a user."

It is important to distinguish between the various levels of interaction. Bannon (1991) has highlighted the case of discretionary users who might use computers to assist with everyday tasks but who have alternative means of accomplishing them. If an information retrieval systems is built on the assumption that all users work at an operational level then discretionary users, for whom the use of the system is in itself a significant activity, will reject the system

\section{CONCLUSION}

Psychology has a long way to go before it will be readily accepted by technology developers as a basis for their design. It is possible that part of the problem has been the incomplete model inherent in cognitive psychology although there is strong evidence that most developers pay scant regard to any form of psychology when developing new systems. In Vygotskian activity theory designers have a model which is more complete and could certainly provide some benefits to human centred interfaces. A philosophical basis for the inclusion of technology into our lives must seek to place human considerations first - a possibility only if sound human psycholgy is available to technology builders.

\section{REFERENCES}

Aboulafia, A., Nielsen, J., Jorgensen, A.H. (1993) The Ambiguous Reality and Formal Methods in User Interface Design, Interchi'93 Research Symposium, Amsterdam. April 1993.

Bannon,.L. (1991) From Human Factors to Human Actors, in Greenbaum \& King, (Eds), Design at Work, Erlbaum, NJ.

Bannon, L. and Bodker, S. (1991) Beyond The Interface: Encountering Artifacts in Use, in Carroll J. (Ed), Designing Interaction, Psychology At The Human-Computer Interface, Cambridge University Press.

Bansler, J. P. and Boedker, K. (1993) A Reappraisal of Structured Analysis: Design in an Organisational Context, ACM Transactions on Information Systems, Vol. 11, No.2, April 1993.

Bødker, S. (1997) Computers in Mediated Human Activity, Mind, Culture and Activity, 4(3), pp149-158.

Bødker, S. (1991) Through The Interface: A Human Activity Approach To User Interface Design, Lawrence Erlbaum, Hillsdale, NJ.

Brooks, R.A. (1991) Intelligence Without Reason, Proceedings of the 12th International Joint Conference on Artificial Intelligence, Vol 1, Sydney

Brown, D.E. and White, C.C. (1990) Operations Research and Artificial Intelligence, Kluwer Academic Press, Mass, USA

Cole, M. and Maltzman, I., (Eds) (1969) A Handbook of Contemporary Soviet Psychology, Basic, NY.

Draper, S. (1993), Activity Theory: The New Direction For HCI?, Intl Journal of Man Machine Studies, Vol 24.

Dreyfus, H.L. and Dreyfus S.E. (1986) Mind Over Machine, Free Press (Macmillan), NY

Dreyfus, H.L. (1992) What Computers Still Can't Do, A Critique of Artificial Reasoning, MIT, Cambridge, Mass.

Engestrom, Y. (1990) Learning, Working and Imagining - Twelve Studies in Activity Theory, Orientakonsultit Oy, Helsinki

Feigenbaum, E. A. (1977) The Art of Artificial Intelligence: Themes and Case Studies of Knowledge Engineering. 5th Intl Conference on Artificial Intelligence AI-77, pp1014-1024.

Gould, E. and Verenikina, I. (1995) Population Modelling Design Based on an Activity Theory, 6th Congress on Activity Theory, Moscow, pp 134-138.

Hasan H, Gould E. and Hyland P. (Eds.) (1998) Information Systems and Activity Theory: Tools in Context, University of Wollongong Press, Wollongong, Australia

Howes, A. (1994) Learning to Use An Interface: Articulating the Space of Models, Proceedings of CHI'94 Research Symposium, Boston Mass. 
Hyland, P. (1998) Exploring Some Problems in Information Retrieval: An Activity theory Approach in Hasan, H., Gould, E and Hyland, P. (Eds), Information Systems and Activity Theory: Tools in Context, University of Wollongong Press, Wollongong, Australia, pp 93-108.

Kaptelinin, V (1992) Human-Computer Interaction in Context: The activity Theory Position, Proceedings EastWest Intl. Conference on Human-Computer Interaction, St Petersburg, Russia.

Kaptelinin, V. (1994), Activity Theory: Implications For Human Computer Interaction, In Brouwer-Janse, M.D. and Harrington, T.L., (Eds), Human-Machine Communication For Educational Systems Design, NATO ASI Series. Series F: Computer and Systems Sciences, v.129, Springer-Verlag, Berlin, pp 5-16.

Kaptelinin, V and Nardi, B. (1997) The Activity Checklist: A Tool for Representing the "Space" of Context, personal communication with authors.

Karpatschof, B. (1992) The Control Of Technology And The Technology Of Control, Multidisciplinary Newsletter For Activity Theory, 11/12, International Standing Conference for Research on Activity Theory (ISCRAT), Berlin.

Kuutti, K. (1990) Activity Theory and its Application to Information Systems Research and Development. In: ISRA90 Proceedings - Vol. I, IFIP TC 8 WG 8.2. Working Conference on the Information Systems Research Arena of the 90's, Copenhagen.

Kuutti, K (1992) HCI Research and Activity Theory Position, Proceedings East-West Intl. Conference on Human-Computer Interaction, St Petersburg, Russia.

Leontiev, A.N. (1978) Activity, Consciousness And Personality, Prentice-Hall, Engelwood Cliff, NJ.

Leontiev, A.N. (1981) Problems of the Development of the Mind, Progress Publishers, Moscow.

McCorduck, P. (1979) Machines Who Think, Freeman and Company, San Francisco

Nardi, B. (1992) Studying Context: A Comparison of Activity Theory, Situated Action Models and Distributed Cognition, Proceedings East-West Intl. Conference on Human-Computer Interaction, St Petersburg, Russia.

Nardi, B (1997), Context and Consciousness: Activity Theory and Human Computer Interaction, MIT Press, Boston, Mass

Pennel, R, Durham, M, Conrad, O. and Spark, T.(1997) Writing In Context: Situated Learning on the Web, Proceedings of ASCILITE '97, Perth, WA.

Raeithel, A (1990) Production of Reality and Construction of Possibilities: Activity Theory Answers To The Challenge of Radical Constructivism, Multidisciplinary Newsletter For Activity Theory, Vol 5/6, International Standing Conference for Research on Activity Theory (ISCRAT), Berlin.

Suchman, L.A. (1987) Plans and Situated Actions: The Problem of Human Machine Communication, Cambridge University Press.

Tikhomirov, O.K. (1988) The Psychology of Thinking, Progress Publishers

Tolman, C.W. (1988) The Basic Vocabulary of Activity Theory, Multidisciplinary Newsletter For Activity Theory, Vol 1 , International Standing Conference for Research on Activity Theory (ISCRAT), Berlin

Verenikina, I. and Gould, E. (1997) Activity Theory as a Framework for Interface Design, ASCIITE'97, Perth WA, pp 611-615.

Vygotsky, L.S. (1981) The Instrumental Method in Psychology. In Wertsch, J. V., (Ed), 1981, The Concept of Activity in Soviet Psychology, Armonk, NY: Sharpe.

Vygotsky, L.S. (1978) Mind in Society: The Development of Higher Psychological Processes, Harvard University Press.

Warren, C. (1992) HCI- Where's The Practice?, Int. J. Man-Machine Studies, Vol 37, p 811-812.

Wersch, J. W. (1981) The Concept of Activity in Soviet Psychology, An introduction. in Wertsch, J. V.(Editor), The Concept of Activity in Soviet Psychology, M. E. Sharpe, Inc., Armonk, New York.

Wertsch, J.V. (1994) The Primacy of Mediated Action in Sociocultural Studies, in Mind, Culture and Activity: An International Journal, Vol 1 No 4, Fall, Laboratory of Comparative Human Cognition, UCSD, Ca.

Winograd, T and Flores, F. (1986) Understanding Computers and Cognition: A New Foundation For Design, Ablex, NJ.

Zinchenko, V.P.1(992) Activity Theory: Retrospect and Prospect, Proceedings East-West Intl Conference on Human Computer Interaction, St Petersburg, Russia. 


\title{
BOOK REVIEW
}

\author{
Keith Curle \\ CAMINER, D., ARIS, J., HERMON, P., and LAND F., (contributors \& editors). (1998). \\ LEO: The Incredible Story of the World's First Business Computer. \\ McGraw-Hill New York. 392 pp.
}

As a book devoted to the pioneering days of computing, this would have to be a nostalgic journey to anyone who was involved in the data processing and computer industry in the $1950 \mathrm{~s}$ and early $1960 \mathrm{~s}$. The four contributors whose names appear on the cover are only some of the early pioneers who have participated in writing their versions of those early days when they were involved in the painstaking development of this, the first computer specifically designed for business. In all, twelve of the team have put their memories on paper and contributed to this book. They discuss the struggle and difficulty of building the LEO (Lyons Electronic Office) computer considering there were no true business computers, in fact only a few scientific computers existed and they were mostly sitting in electronics laboratories in universities. In fact the LEO computer was a variation of the EDSAC, a scientific computer developed in the Mathematics Laboratory of Cambridge University. It is interesting to note that the internal political manoeuvrings within the company played a role in the development process and are looked at in retrospect. The writers look at Lyon Tea Houses, an entrepreneurial British company who were the country's largest distributor of food and beverages and were running a nation-wide complex of restaurants and tea houses. Lyons had been around since the 1890s and had always been innovative in their approach to business and by 1947 felt the need for a better method of processing their large quantities of statistical as well as other data. By giving Cambridge University a grant to enable them to complete EDSAC they were able to borrow from their expertise when the University's computer was completed and tested in 1949. At this time, the board of Lyon Tea Houses approved the building of LEO. David Caminer then describes the construction of LEO by following the Cambridge drawings and modifying parts of the circuitry and architecture to that which suited a business environment. One quote which seems very pertinent is,

"The first machine we built, LEO Mark 1, was based on the logic of EDSAC Mark 1. The philosophy we had was that we would not change anything if we didn't understand why it was done the way it was. So to start with, since we didn't understand very well why it was done the way it was, we didn't make very many changes at all."

The description of their experiences is very entertaining, one thing that the reader will note is the very British way in which people are addressed when discussing their roles. In many cases, given names are not used, instead only the formal title of Mister or Miss. If there is one complaint about the content, it would have to be the way David Caminer is intent on mentioning the name of every person he can recollect being associated with the project, even if they have only a minuscule involvement. The first computer was completed in 1951 and once tested was used for running a large statistical program for Lyons. Surplus time was sold in a bureau type operation programming for which involved not only LEO staff but advisers from the user company. When you consider that all the programming in these early days was carried out in machine language it isn't difficult to imagine what a mammoth task it was. Of course some subroutines for repetitive operations were written and called when required, but nothing was easy. One of the slowest processes was program writing and testing. Because of its workload, testing time for new programs was difficult to obtain especially when there was a considerable amount of bureau work for other companies such as the Ford Motor Co. and Stewart \& Lloyds. The most hype in the industry was centered in the USA where IBM were working frantically to match the Remington Rand Univac, a struggle described in the book Father Son \& Co. [(1990) Bantam] where Thomas J. Watson Jnr., describes IBM's frantic efforts to make up lost ground. Probably neither company paid a great deal of attention to the LEO project which was technically superior to anything produced at that time by either of the American corporations.

For readers who have only entered the computer industry over the last decade or so it is interesting to note that LEO was using a stored program (by way of mercury vapour delay lines) and even though input was by way of punched paper tape it was really years ahead of its time. However by 1954 it had run out of capacity and there were many areas of the architecture which the LEO staff realised could be improved upon, consequently LEO Mark II was given the go-ahead. Once again it used paper tape and punched cards for input and mercury vapour delay lines for storage, output however was greatly improved. Once this new LEO was introduced in 1957 it became the most 
advanced stored program computer in the business environment. The most advanced of the IBM computers was the 700 series which used ferrite core memory, but it still wasn't up to the performance of the LEO II. Later productions of the LEO Mark II/2 replaced the mercury vapour delay lines with ferrite core storage as well. The narrative goes on to describe how the IBM 1401 entered the market in 1959 and orders were taken which made severe inroads into the British computer market. The sales motto being expressed by the aggressive IBM team was,

"Nobody has ever been fired for buying IBM."

In the next phase of the story, the reader is taken through the halcyon days of LEO with their second generation model, the LEO III. This was designed in 1960 and by 1961 it had been tested and orders taken. They began selling them in 1962. At this point in time LEO III was the most advanced business computer in the world, with the ability to multi-program and with fast peripheral equipment. Later, in 1963 the last of the LEO models was produced, the LEO 326. LEO's were being sold overseas at this time and would probably have continued developing except for the introduction of the IBM 360 together with IBM's aggressive marketing policy. The Lyon's Company were very profit oriented and were disappointed that they were still not seeing any profits from their computer subsidiary, and sold off LEO to the English Electric Company in two stages. The LEO III and 326 were still produced until 1968 at this time English Electric merged with ICT to form ICL.

David Caminer's account ends half way through the book whereupon others from the group of development pioneers begin telling their stories. Their accounts are mostly associated with applications for specific customers and details how they organised their programming and operations. One of the most interesting sections for me, having come from a background in hardware, was by T.R.Thompson and O.W.Standingford, two of Lyon's executives who travelled to the USA in 1947 to evaluate the state of development of electronic computers. They undertake technical descriptions and drawings of the devices employed at that time and for anyone who remembers vacuum tube operated computers, it is intensely interesting. After reading this section it would be a good exercise to sit down at your Pentium 266 MMX with 64MB RAM and its CD ROM drive and 6GB hard disk, SVGA screen and possibly a colour scanner and laser or inkjet printer and ponder the progress made since LEO Mark 1 first ran a program 47 ago. 